\title{
STUDY OF WORK RELATED RESPIRATORY SYMPTOMS AMONG WELDING WORKERS
}

\author{
ARSHAD HUSAIN RAHMANI ${ }^{1 *}$, ALI ABBAD AL-HURABI ${ }^{1}$, REJO JACOB JOSEPH ${ }^{2}$, ALI YOUSIF BABIKER ${ }^{1}$
}

${ }^{1}$ Department of Medical Laboratories, College of Applied Medical Sciences, Qassim University, Buraidah, Saudi Arabia. ${ }^{2}$ Department of Basic Health Sciences, College of Applied Medical Sciences, Qassim University, Buraidah, Saudi Arabia. Email: rehmani.arshad@gmail.com

Received: 25 September 2017, Revised and Accepted: 28 October 2017

ABSTRACT

Introduction: Occupational and environmental pollutant is one of the culprits of morbidity and mortality. Welding materials or fumes of welding materials causes pathogenesis of diseases including asthma, tuberculosis, chest tightness, and other lungs diseases.

Objective: The objective of this study was to examine the effect of welding fumes on workers and its correlation with smoking and chewing habits.

Methods: A total of 44 occupationally exposed worker of welding material in 10 different units were included in this study. A pre-textured questioner was used to inquire duration of work, smoking, chewing, and health related issue. Moreover, sputum samples were collected for the cytological analysis through papanicolaou staining.

Results: The subjects were distributed according to health-related issue, and it was observed that back pain was in 8 subjects (18.18\%), respiratory disorder including acute cough was in 4 (9.09\%), asthma was noted in 5 (11.36\%), vision problem in 4 (9.09\%), skin rashes in 5 (11.36\%), and other health problem was in 3 (6.81\%). Cytological analysis was made and observed that 15 (34.09\%) subjects out of 44 showed acute inflammation. In addition, diseases linked with respiratory systems such as asthma, chest tightness/acute cough, and other respiratory problem was high in the workers who have long exposure of the welding materials. Furthermore, the subjects who have a history of smoking, chewing, and long work duration showed a high prevalence of health-related complications.

Conclusion: This result is indicating that exposure to welding material for long time causes an alteration in epithelial cells that permit easier attack of microbes and thereby finally causes inflammation.

Keywords: Welding workers, Respiratory symptoms, Inflammation.

(C) 2018 The Authors. Published by Innovare Academic Sciences Pvt Ltd. This is an open access article under the CC BY license (http://creativecommons. org/licenses/by/4. 0/) DOI: http://dx.doi.org/10.22159/ajpcr.2018.v11i2.22767

\section{INTRODUCTION}

Environmental and occupational pollutant is one of the major culprits in the morbidity and mortality. Numerous diseases including asthma, tuberculosis, and chronic obstructive pulmonary disease have been reported due to occupational and environmental pollution. Incidence of occupational and environmental disease is continuously increasing throughout the world. In this vista, welding materials or fumes of welding materials has proven role in the pathogenesis of diseases including tuberculosis, chest tightness, and other lungs diseases. The principal factor accountable in this phenomenon is still to be explained, and mechanism of action is not understood fully. However, it is considered that hazardous material released by industry or exposure to occupational and environmental pollution causes health-related complications in the workers. Numerous hazards associated with welding occupation such as ultraviolet and infrared radiation exposure, particulate generation and occupational heat stress [1] and welding fumes include much higher particle concentrations than outdoor ambient air [2-4]. Hazards materials released by welding fumes cause pathogenesis of various diseases. In general, adverse health effects including respiratory and non-respiratory are reported in such workers, and health complications in the workers include bronchitis, pneumonia, metal fume fever, and neurological effects [3-5]. Welding fumes or material released during the welding process are one of the culprits in the development of lung diseases and causes tissue damage, injury and pathogenesis of various diseases. Moreover, pollutants released at the workplace are inhaled and enter to the bloodstream through respiratory air and taken up by the digestive and respiratory systems, and finally, such pollutant shows the effect as tissue damage $[6,7]$. The aim of this study was to examine the effect of welding fumes or hazards materials of welding on workers.

\section{METHODS}

It was a community-based cross-sectional study conducted among welding workers in the city of Unizah, Qassim Province of Saudi Arabia. The study had prior approval from research committee on the graduation project under which this work was conducted. A total of 44 occupationally exposed worker of welding material in 10 different units were included in the study. The age of welding worker ranged from 20 to 55 years. A textured questionnaire was used to inquire the age, duration of work, smoking, chewing, and health-related issue.

\section{Sample collection and processing}

Sputum samples with deep cough were collect in the plastic jar in the evening time. Samples were centrifuged and smear was made on the slides and fixed with methanol. Cytological analysis was made through papanicolaou stain and result was interpreted with the help of light microscopy.

\section{RESULTS}

\section{Disruption of subjects based on age}

Of the 44 cases studied, there were 12 cases (27.27\%) in the age group $<25$ years, $20(45.45 \%)$ in the age group 25-45 years, and 12 cases $(27.27 \%)$ in the age group more than 45 years (Fig. 1 ).

\section{Disruption based on addiction habits}

A details history of subjects was taken to find out the cause of disease. The subject was divided into 3 groups; 1 - smokers, 2-chewers, and 3-both (smokers and chewers). 
12 subjects $(27.27 \%)$ were only smoker, 19 subjects $(43.18 \%)$ were chewers, and 7 subjects (15.96\%) were both smoker and chewers (Table 1 and Fig. 2).

Disruption based on duration of work (number of years)

All the subjects were divided on the basis of a number of years work duration as; 19 (43.18\%) were working <5 years, $12(27.27 \%)$ has 5-10 years exposure of welding material, and 13 (29.54\%) subjects were working more than 10 years (Fig. 3).

\section{Disruption based on health-related complications}

The subjects were distributed according to health-related issue, and it was observed that back pain was in 8 subjects (18.18\%), respiratory disorder including acute cough/chest tightness was in 4 (9.09\%), asthma was noted in $5(11.36 \%)$, vision problem in 4 (9.09\%), skin rashes in $5(11.36 \%)$, and other health problem was in $3(6.81 \%)$ (Fig. 4).

\section{Cytological analysis}

Samples were analyzed through cytological staining to check the cellular alterations. Cytological analysis was made and observed that $15(34.09 \%)$ subjects out of 44 showed acute inflammation (Fig. 5). When we analyzed these according to work duration and health-related issue, we noted that most of the subjects has long work exposure and also has diseases linked with respiratory disorder such as asthma, chest tightness, and other respiratory problem. This result is indicating that exposure to welding material for a long time causes an alteration in epithelial cells that permit easier attack of microbes and thereby finally causes inflammation.

Table 1: The distribution of subjects according to addictions

\begin{tabular}{ll}
\hline Types of addiction & Total subjects (\%) \\
\hline Smokers & $9(20.45)$ \\
Chewers & $12(27.27)$ \\
Both (smokers and chewers) & $7(15.90)$ \\
\hline
\end{tabular}

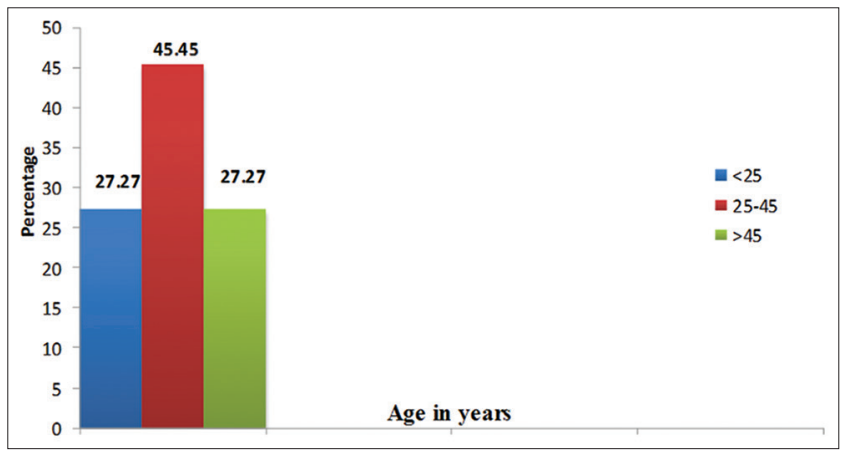

Fig. 1: Distribution of subjects on the basis of age

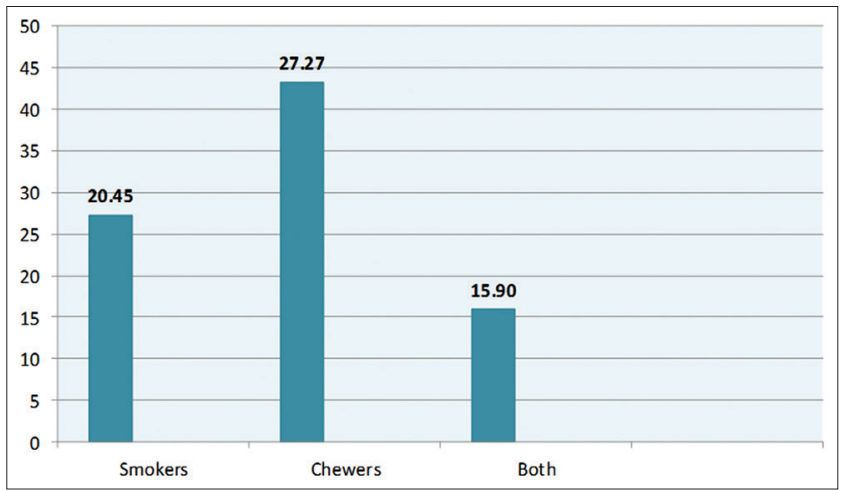

Fig. 2: Distribution of subjects on the basis of addiction habits
Smoking, chewing and work duration interpretation

The subjects who have a history of smoking, chewing and long work duration showed a high prevalence of health-related issues such as asthma and respiratory disorder. Out of 5 asthma cases, we found that $4(80 \%)$ subjects were having more than 5 years exposure and worked for long duration (around 5-6 h per day) and in 3 out of 5 same subject groups having history chewing and smoking. 4 subjects showed respiratory symptoms were divided on the basis of work duration and it was found that three subjects have more than 5 years exposure of welding material. The data are indicating that long-time exposure of fumes or welding materials cause lung related diseases or complications. In addition, smoking and chewing show additive effect on the pathogenesis.

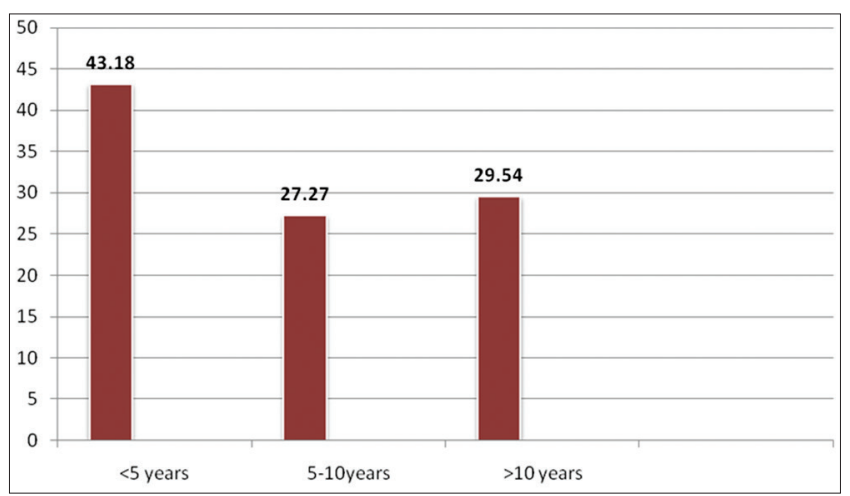

Fig. 3: Distribution of subjects on the basis of duration of work

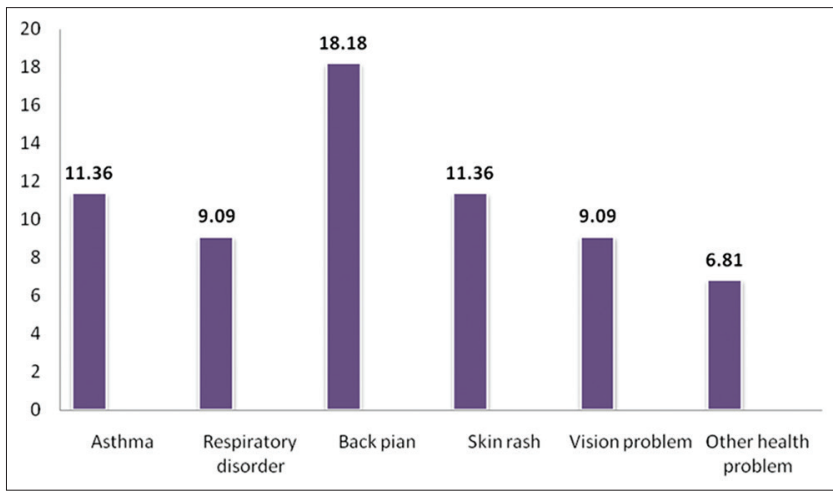

Fig. 4: Distribution of subjects on the basis of health-related complications

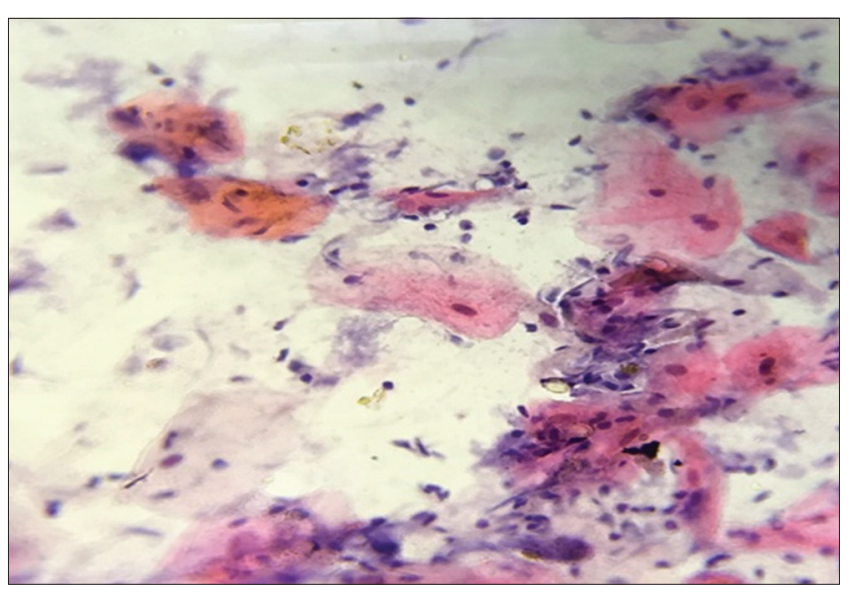

Fig. 5: Papanicolaou staining showing inflammatory cells (Original $\times 40$ ) 


\section{DISCUSSION}

The incidence and prevalence of various diseases are associated with occupational and environmental pollutant and pathogens. A study was made to analyze the prevalent risk factors of Hepatitis C Virus (HCV) transmission in Health Care Workers and result of the study showed that the mean prevalence of HCV in HCWs was reported $4.46 \% \pm 2$ [8].

Another finding reported that cytotoxic effect of carbon nanoparticles and it was greater than quartz particles [9]. Fumes or hazards produced during the welding process cause various health-related complications including respiratory disease and asthma. In this regard, previous studies have reported that fumes of welding exposure might be a cause of asthma [10-12]. In current finding, the incidence of respiratory disease was $20.45 \%$. Study was performed to evaluate the effect of welding fumes on respiratory symptoms in welders, compared with a control group of electricians. Finding reported that welders showed a significantly higher prevalence of chronic bronchitis: $21 \%$ versus $9 \%$ in the control group [13]. Moreover, other studies reported that respiratory complaints/symptoms are common among welders due to the exposure of welding emissions $[14,15]$. In our study, we noticed that respiratory symptoms including chest tightness and asthma were more prevalent among workers who have long work history as compared to workers who have less exposure history. The current study also shows that prevalence of respiratory was high in welding workers as compared. Other study reported that respiratory complaints especially chronic bronchitis were high among welders as compared with the non-exposed group that indicates to be the result of welding emissions [16]. The exact mechanism of disease development due to the fumes exposure is not understood completely but it is thought that the inhalation of fumes or gases produced by welding process causes an alteration in epithelial cells or suppresses the first line of defense. Moreover, our finding reported that acute inflammation was seen in the workers who have long duration work history as compared to less exposed workers.

The finding concluded that high prevalence of respiratory diseases or symptoms in workers who have long duration history and that indicates that fumes or materials of welding cause pathogenesis of diseases and suppression of the first line of defense.

\section{AUTHOR'S CONTRIBUTION}

Mr. Ali and Mr. Rejo contributed in performing the experiment and data compilation. Dr. Arshad and Dr. Ali Yousif were involved in experimental design, draft the manuscript and corrections of the manuscript as per journal requirement.

\section{CONFLICT OF INTEREST}

None.

\section{REFERENCES}

1. Shaikh TQ, Bhojani FA. Occupational injuries and perception of hazards among road-side welding workers. J Pak Med Assoc 1991;41:187-8.

2. Lehnert M, Pesch B, Lotz A, Pelzer J, Kendzia B, Gawrych K, et al. Exposure to inhalable, respirable, and ultrafine particles in welding fume. Ann Occup Hyg 2012;56:557-67.

3. Antonini JM. Health effects of welding. Crit Rev Toxicol 2003;33:61103.

4. Gidhagen L, Omstedt G, Pershagen G, Willers S, Bellander T. Highresolution modeling of residential outdoor particulate levels in Sweden. J Expo Sci Environ Epidemiol 2013;23:306-14.

5. Zeidler-Erdely PC, Erdely A, Antonini JM. Immunotoxicology of arc welding fume: Worker and experimental animal studies. J Immunotoxicol 2012;9:411-25.

6. Jelmert $\mathrm{O}$, Hansteen IL, Langård S. Cytogenetic studies of stainless steel welders using the tungsten inert gas and metal inert gas methods for welding. Mutat Res 1995;342:77-85.

7. Kalliomäki PL, Kalliomäki K, Korhonen O, Nordman H, Rahkonen E, Vaaranen V. Respiratory status of stainless steel and mild steel welders. Scand J Work Environ Health 1982;8 Suppl 1:117-21.

8. Zia A, Ullah I, Ali S, Zia M, Mathew S, Fatima K, et al. Prevalent risk factors of $\mathrm{HCV}$ transmission in health care workers (HCWS) in Pakistan. Int J Pharm Pharm Sci 2015;7:365-70.

9. Angoth B, Lingabathula H, Gandamalla D, Yellu NR. Cytotoxicity evaluation of carbon nanomaterials on human cell lines using MTT assay. Int J Pharm Pharm Sci 2014;6:379-82

10. Wang ZP, Larsson K, Malmberg P, Sjögren B, Hallberg BO, Wrangskog K. Asthma, lung function, and bronchial responsiveness in welders. Am J Ind Med 1994;26:741-54.

11. Beach JR, Dennis JH, Avery AJ, Bromly CL, Ward RJ, Walters EH, et al. An epidemiologic investigation of asthma in welders. Am J Respir Crit Care Med 1996;154:1394-400.

12. Torén K, Järvholm B, Brisman J, Hagberg S, Hermansson BA, Lillienberg L. Adult-onset asthma and occupational exposures. Scand J Work Environ Health 1999;25:430-5.

13. Groth M, Lyngenbo O. Respiratory symptoms in Danish welders. Scand J Soc Med 1989;17:271-6.

14. Loukzadeh Z, Sharifian SA, Aminian O, Shojaoddiny-Ardekani A. Pulmonary effects of spot welding in automobile assembly. Occup Med (Lond) 2009;59:267-9.

15. Bradshaw LM, Fishwick D, Slater T, Pearce N. Chronic bronchitis, work related respiratory symptoms, and pulmonary function in welders in New Zealand. Occup Environ Med 1998;55:150-4.

16. Al-Otaibi ST. Respiratory health of a population of welders. J Family Community Med 2014;21:162-5. 